\title{
OBSERVATIONS ON A STRAIN OF NEISSERIA MENINGITIDIS IN THE PRESENCE OF GLUCOSE AND MALTOSE
}

\author{
I. Growth Studies ${ }^{1}$ \\ CHARLOTTE FITTING AND HENRY W. SCHERP \\ Department of Bacteriology, School of Medicine and Dentistry, University of Rochester, \\ Rochester 20, New York
}

Received for publication November 24, 1950

This report concerns the differential utilization of the disaccharide maltose and of its constituent monosaccharide glucose by a strain of Neisseria meningitidis. In the presence of maltose the organism produced changes which in the presence of glucose either were not detected or appeared at a greatly reduced rate. For example, it was noted that inorganic phosphate disappeared only with maltose and the decrease of reducing substances, and the production of acid occurred to a greater extent in the presence of maltose than it did with glucose. Similar observations were made with growing cultures, with washed-cell suspensions in which the organism was in the so-called "resting state," and with "cell-free" extracts. Growth studies are emphasized here. Work on the other two test systems will be recorded subsequently.

According to Fischer's theory (1898) of the indirect utilization of a compound sugar, microorganisms hydrolyze the oligosaccharide into its constituent simple sugars before the process of fermentation can take place. On the other hand, Willstätter and Rohdewald (1937) showed that a yeast converted maltose completely into a polyose, which then was fermented. These findings were interpreted to indicate a direct utilization of the complex sugar without its preliminary hydrolysis. Recent reports published from Doudoroff's (1949) and Monod's (1950) laboratories suggest a resolution of these theories by their description of the action of various "transglucosidases." The preferential utilization of oligosaccharides by bacteria is considered to depend upon adaptive processes in the sense of Karström (1938). Our observations indicate that a strain of Neisseria meningitidis utilizes maltose more rapidly than glucose as a result of a training process "due to the selection of variants which occur under normal conditions in the parent culture" (Dubos, 1945). This selective process was found to depend upon the concentration of inorganic phosphate and upon the type of sugar present in the culture medium.

${ }^{1}$ The data presented in this paper were taken from a thesis submitted in June, 1950, by Charlotte Fitting to The University of Rochester in partial fulfillment of the requirements for the degree Doctor of Philosophy. The study was supported by a contract (N6-ori-126, Task III) between The University of Rochester and the Office of Naval Research. This contract stipulates that "Reproduction in whole or in part is permitted for any purpose of the United States Government." Part of the material was presented before the 50th General Meeting of the Society of American Bacteriologists in Baltimore, Maryland, on May 15, 1950 (Fitting and Scherp, 1950). 


\section{MATERIALS AND METHODS}

Cultures. Neisseria meningitidis, strain 69 (type I), was preserved by desiccation from the frozen state and was sealed in vacuo in the original all-glass container. The history of this old laboratory culture has been described previously (Scherp and Fitting, 1949). For an experiment, the contents of such a glass tube were taken up in a small amount of physiological saline and transferred to blood agar plates. No culture was used after more than five daily subcultures. Unless otherwise noted all cultures were incubated in closed containers at $37 \mathrm{C}$.

In contrast to strain 69 , eight other strains had been stored in the desiccated state as soon as possible after their primary isolation from patients having a meningococcal infection, or were laboratory strains of proved virulence for mice. Seven of these cultures were type I and one was type II-alpha.

TABLE 1

Composition of variations of the Frantz medium used in this study

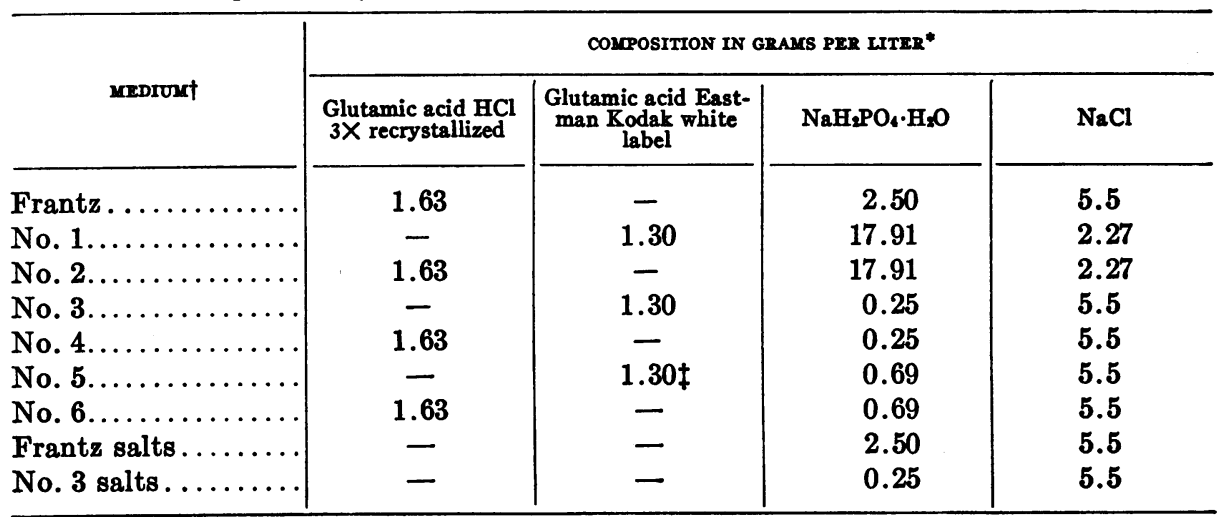

${ }^{*} \mathrm{KCl}, 0.09 \mathrm{~g} ; \mathrm{MgSO}_{4} \cdot 7 \mathrm{H}_{2} \mathrm{O}, 0.60 \mathrm{~g}$; and $\mathrm{NH}_{4} \mathrm{Cl}, 1.25 \mathrm{~g}$, were added to all mixtures; the first seven media also contained $0.012 \mathrm{~g}$ of L-cystine and $5.0 \mathrm{~g}$ of either glucose or maltose.

$\dagger$ The $\mathrm{pH}$ was adjusted to $7.3( \pm 0.2)$ with sodium hydroxide.

$\ddagger$ Eastman Kodak glutamic acid, practical grade.

Media. The basic culture medium was that described by Frantz (1942). The composition of the various media used in this study is presented in table 1 , from which it can be seen that the differences concerned the chemical purity of L-glutamic acid, the concentration of inorganic phosphate, and the sugar used. The media were prepared in the manner described by Scherp and Fitting (1949) except for media no. 5 and no. 6 . Since the latter were used for determining the rate of acid production, phenol red was added as the indicator in a final concentration of 0.0008 per cent. These media were made up without the addition of the sugars or of the magnesium sulfate and were sterilized in the autoclave at $116 \mathrm{C}$ for 10 minutes. A solution containing $25 \mathrm{~g}$ of the respective sugar and $3 \mathrm{~g}$ of magnesium sulfate per $100 \mathrm{ml}$ was sterilized by filtration and was added aseptically to the rest of the medium in the proportion of 2 per cent by volume.

Glucose-1-phosphate was prepared as the dipotassium salt by the method 
of Sumner and Somers (1944). It was recrystallized at least twice before use. Maltose and glucose were purified by recrystallization in 65 per cent ethanol. Difco maltose was used.

Analytical methods. Ammonia nitrogen was determined on trichloracetic acid filtrates of the cultures by the Parnas method.

Carbonyl compounds (referred to as "keto acid") were converted to the hydrazone with 2,4-dinitrophenylhydrazine and compared to a standard solution of lithium pyruvate according to the procedure of Sealock (1941).

Lactic acid was measured by the method of Barker and Summerson (1941). $p H$ was measured with a glass electrode.

Phosphorus analyses were made on trichloracetic acid filtrates of the cultures by the method of Lowery and Lopez (1946). Since these analyses were carried out at $\mathrm{pH} 4.0$, the possibility of the hydrolysis of some of the organic phosphate esters was greatly reduced. The values obtained were assumed, therefore, to represent inorganic phosphate alone.

Reducing substances (referred to as "glucose") were determined on Somogyi (1930) filtrates of the cultures by the method of Schales and Schales (1945), and in the earlier experiments on the rate of total acid production by the organisms, Hanes' (1929) method was used.

Growth was measured by reading the turbidity of aliquots of the cultures in a Klett-Summerson photoelectric colorimeter with filters no. 42 or no. 54 . The scale readings were recorded. It was determined that with filter 42 a scale reading of 40 was equivalent to an average cellular concentration of $3 \times 10^{8}$ cells per $\mathrm{ml}$ of suspension as determined by a plate count method.

Total acidity was titrated with $1 \mathrm{~N}$ sodium hydroxide at intervals so that a $\mathrm{pH}$ range of 7.0 to 7.4 was maintained during the growth of the cultures.

Volatile acids were analyzed by the method of Osburn, Wood, and Werkman (1936).

Experimental procedures. In the early experiments comparing the rates of accumulation of acid from glucose and from maltose by different strains of meningococci, starter cultures in $50 \mathrm{ml}$ of medium in 200-ml Erlenmeyer flasks were inoculated with a loopful of the growth on a blood agar plate. After 24 hours' incubation $2.5 \mathrm{ml}$ of the starter culture were transferred to each experimental flask ( $250 \mathrm{ml}$ of medium containing the same sugar as the starter culture in a 1-liter Erlenmeyer flask). With these relatively heavy inocula supplemental carbon dioxide was unnecessary to initiate rapid multiplication of the organisms. Each experimental flask was closed with a no. 8 rubber stopper bearing a burette containing $1 \mathrm{~N}$ sodium hydroxide and two glass tubes filled with cotton. Gentle suction applied to one of the tubes provided aeration. The alkali was added as needed to maintain the cultures within the $\mathrm{pH}$ range from 7.0 to 7.4. At first quadruplicate flasks were tested for each sugar. Since the amounts of acid formed in replicates generally agreed within 10 per cent, a single flask was used for each sugar in the experiments recorded in table 2 except for those on strains no. 69 and no. 520, for which the average values of quadruplicate flasks are given.

For the more detailed work on strain 69 the inocula were prepared in one of 
two ways. In the majority of experiments with media nos. 1 and 3, the organism was transferred from blood agar to a 125-ml Erlenmeyer flask which contained $25 \mathrm{ml}$ of the respective medium (with glucose or without glucose, as will be indicated) and was incubated at $37 \mathrm{C}$ for 24 hours. At that time $0.25 \mathrm{ml}$ of this culture (i.e., approximately 25 to $75 \times 10^{6}$ cells) was used as the inoculum for $25 \mathrm{ml}$ of medium. For growth experiments with the Frantz media and media nos. 2 and 4 the culture was transferred by needle from blood agar to a 125-ml Erlenmeyer flask, which contained $25 \mathrm{ml}$ of the Frantz-glucose medium and was incubated at $37 \mathrm{C}$ for 24 hours. This culture was used to inoculate all the other experimental flasks.

In these growth studies the media were dispensed in Erlenmeyer flasks. Most often $25 \mathrm{ml}$ of the medium per 125-ml flask were used. At least triplicate flasks of any one particular medium were inoculated in as uniform a manner as possible and were incubated at $37 \mathrm{C}$. Two uninoculated flasks served as controls. At the specified time intervals all or only half of the experimental flasks were sampled.

To test the ability of the organism to grow in some of the media, determinations were made of the minimal inoculum that sufficed to initiate growth. Serial decimal dilutions of the inoculum were prepared in the conventional manner by successive transfers of $0.5 \mathrm{ml}$ into $4.5 \mathrm{ml}$ of the test medium contained in 6-by- $\frac{-3}{4}-$ inch test tubes. The presence of growth was judged by the development of turbidity after 24 and 48 hours' incubation and was confirmed in critical tubes by subculture on blood agar.

The culture samples were checked for purity by gram-staining and also by subculturing on blood agar.

\section{RESULTS}

Acid accumulation during the growth of nine strains of Neisseria meningitidis in medium no. 5 was found to occur more rapidly in the presence of maltose than with glucose. This differential was especially pronounced with strain 69 , which in contrast to the other cultures was an old laboratory strain. It had reverted to the avirulent "stock" form described by Rake (1933). The total amounts of acid produced from each sugar are recorded in table 2, which indicates the range of results obtained after the accumulation of acid from maltose had reached an equilibrium (from 8 to 11 days). Substitution of thrice recrystallized L-glutamic acid hydrochloride for the Eastman Kodak practical grade failed to influence the rate of acid accumulation from either sugar by strain 69 . It was possible then to follow some of the metabolic changes of the culture during its growth in an environment defined by the present standards of chemical purity. In glucose cultures of strain 69 from three similar experiments all of the accumulated acid was accounted for as volatile acid whereas only from 39 to 45 per cent of that from maltose was volatile. The volatile acid was identified as acetic acid; five determinations of the partition coefficient, $K_{1}$, ranged from 0.580 to 0.598 with a mean value of 0.590 compared to the value of 0.582 given by Osburn, Wood, and Werkman (1936). Acetic acid has also been identified by Grossowicz (1945) 
among the metabolic products of the meningococcus. Both glucose and maltose cultures formed traces of lactic acid. Only from 1 to 4 per cent of the total amount of acid formed could be attributed to lactic acid. More than half of the acid accumulated in the maltose cultures remained unidentified.

Pelczar and Doetsch (1949) also have shown that four strains of Neisseria produced a drop in $\mathrm{pH}$ when grown in BBL phenol red maltose broth for 7 days. In glucose broth, however, their strains increased the $\mathrm{pH}$ of the medium. Whereas Pelczar and Doetsch observed a decrease in the value of the reducing substances in the maltose cultures only, strain 69 , described here, consumed between 37 and 32 per cent of glucose compared with 82 and 66 per cent of the maltose as measured by the method of Hanes (1929). It became of interest to follow the growth of strain 69 over shorter time intervals so that selective phenomena of

TABLE 2

Rates of acid accumulation from glucose and maltose media by various strains of Neisseria meningitidis

\begin{tabular}{|c|c|c|c|}
\hline \multirow{2}{*}{ STRAIN } & \multicolumn{3}{|c|}{ MTLLIEQUTVALENTS OF ACID IN 250 MC OF MEDIUM } \\
\hline & No. 5 maltose & No. 5 glucose & $\frac{\text { Maltose }}{\text { Glucose }}$ \\
\hline No. $69 . \ldots \ldots \ldots$ & 4.81 & 0.55 & 8.8 \\
\hline No. $520 \ldots \ldots \ldots$ & 8.48 & 5.23 & 1.6 \\
\hline Chilson. ......... & 4.55 & 2.00 & 2.3 \\
\hline Robarge........ & 3.75 & 0.85 & 4.4 \\
\hline Campbell .... & 4.45 & 2.75 & 1.6 \\
\hline $43377(\mathrm{II} \alpha) \ldots$ & 4.15 & 1.95 & 2.1 \\
\hline Card......... & 4.00 & 1.65 & 2.4 \\
\hline Freeman........... & 4.65 & 3.33 & 1.4 \\
\hline \multirow[t]{2}{*}{ Paolino................... } & 4.05 & 1.75 & 2.3 \\
\hline & No. 6 maltose & No. 6 glucose & $\frac{\text { Maltose }}{\text { Glucose }}$ \\
\hline No. $69 \ldots \ldots \ldots$ & 4.29 & 0.58 & 7.4 \\
\hline
\end{tabular}

the cellular populations were minimized. Furthermore, in order to observe comparable inocula the same starter culture (with or without glucose) was used for all the experimental flasks. These populations lacked, therefore, any specific adaptation or selection with respect to maltose. The organism was grown in variations of the Frantz medium (1942) differing in the chemical purity of Lglutamic acid and of the sugars, as well as in the concentration of inorganic phosphate.

Growth of strain 69 in media no. 3 and no. 1 (Eastman Kodak white label glutamic acid and $0.0018 \mathrm{~m}$ and $0.13 \mathrm{~m}$ inorganic phosphate). Preliminary experiments conducted over a period of 1 day with medium no. 3 indicated that strain 69 grew well in the presence of either glucose, maltose, or glucose-1-phosphate. At that time the $\mathrm{pH}$ of the glucose cultures had dropped 0.2 unit in contrast to a drop of 1.3 units in the maltose cultures. In the presence of glucose-1-phos- 
phate an increase was noted of 0.2 unit within 24 hours and of 0.7 unit within 48 hours. However, the concentration of ammonia nitrogen did not change in these cultures. The amount of growth, as measured by scale readings, was similar in the media containing glucose and the Cori ester, but it was 40 to 100 per cent greater in the maltose cultures. Approximately 45 per cent of the maltose (as determined by the diminution of total reducing substances) had disappeared within 48 hours. In the glucose cultures no change in the concentration of reducing substances was noted nor could a change be demonstrated of the phosphorus hydrolyzable in 7 minutes or of the total inorganic phosphate present in the Cori ester cultures. It became evident, therefore, that the organism was capable

TABLE 3

Growth of Neisseria meningitidis (strain 69) in no. 1 medium; glucose vs. maltose

\begin{tabular}{|c|c|c|c|c|c|c|c|c|c|c|}
\hline \multirow{3}{*}{$\begin{array}{c}\text { MEDIUM No. } 1 \\
\text { Hours incubated }\end{array}$} & \multicolumn{10}{|c|}{ ANALYSES* } \\
\hline & \multicolumn{5}{|c|}{ Glucose } & \multicolumn{5}{|c|}{ Maltose } \\
\hline & 19 & 26 & 43 & 69 & 91 & 19 & 26 & 43 & 69 & 91 \\
\hline \multicolumn{11}{|l|}{$\begin{array}{l}\text { Measured as: } \\
\text { pH }\end{array}$} \\
\hline Experimental. & 7.4 & 7.3 & 7.3 & 7.3 & 7.2 & 7.3 & 7.3 & 7.1 & 7.0 & 6.9 \\
\hline Control.... & 7.4 & & & & & 7.4 & & & & \\
\hline Difference..... & 0 & 0.1 & 0.1 & 0.1 & 0.2 & 0.1 & 0.1 & 0.3 & 0.4 & 0.5 \\
\hline $\begin{array}{l}\text { Growth......... } \\
\text { Increase in } \\
\text { "keto-acid" }\end{array}$ & 8 & 21 & 40 & 70 & 85 & 15 & 22 & 65 & 75 & 108 \\
\hline $\begin{array}{c}\mu \mathrm{mole} / \mathrm{ml} \ldots . . . . \\
\text { "Glucose" mg/ml } \\
\text { Experimental. } \\
\text { Control....... } \\
\% \text { decrease.... }\end{array}$ & & 0.00 & 0.00 & 0.01 & $\begin{array}{r}0.00 \\
\\
3.8 \\
5.1 \\
25.5\end{array}$ & 一 & 0.04 & 0.08 & $0.06+$ & \begin{tabular}{|c|}
0.10 \\
\\
1.45 \\
3.5 \\
58.5
\end{tabular} \\
\hline
\end{tabular}

* Each value given is the average of duplicate culture flask samples; deviation in $\mathrm{pH}=$ none; in growth = \pm one scale reading; average deviations of both "keto-acid" and "glucose" analyses $=0.05$.

$\dagger$ One flask only.

of multiplying in the Frantz-amino-acid-salt mixture, apparently without utilizing the Cori ester. Further investigation (Scherp and Fitting, 1949) revealed the existence in the parent population of variants capable of multiplying in the Frantz medium without added carbohydrates or of their intermediary metabolites.

Using the highly buffered medium no. 1, growth curves of strain 69 were obtained over a period of 91 hours. Since the organism did not grow abundantly on the first transfer from blood agar to the glucose medium within the first 24 hours, it was subcultured in the no. 1 glucose broth, and the "selected" population obtained after further incubation for 24 hours was used to inoculate all the experimental flasks. Then the culture grew well in the glucose medium, indicating that the selection was successful for glucose. This selection toward glucose was 
not accompanied by any diminution of the ability of the organism to grow in the maltose medium (table 3). At the termination of the experiment approximately twice as much "maltose" as "glucose" had disappeared. Furthermore, an accumulation of "keto acid" was noted only in the maltose cultures. The need for the organism to be repeatedly exposed to no. 1 glucose medium before rapid growth took place within 24 hours was established in several experiments.

Using a serial dilution method it was observed that the minimal inoculum that sufficed to initiate growth in the high-phosphate medium (no. 1 glucose) was about $10^{4}$ times that required in the low-phosphate medium (no. 3 glucose). These observations provoked two questions: Was the growth-inhibitory property of the high-phosphate medium related to the presence of an inhibitory contam-

TABLE 4

Growth of Neisseria meningitidis (strain 69) in Frantz medium and medium no. 4 with and without glucose

\begin{tabular}{|c|c|c|c|c|c|c|c|c|}
\hline \multirow{2}{*}{ MEDIUY } & \multicolumn{8}{|c|}{ DHLUTION OF INOCOLOY } \\
\hline & $10^{1}$ & $10^{2}$ & $10^{8}$ & 104 & $10^{5}$ & $10^{\circ}$ & $10^{7}$ & $10^{8}$ \\
\hline \multirow{3}{*}{$\begin{array}{l}\text { Frantz } \\
\quad \text { Without glucose } \ldots \ldots \ldots \ldots \ldots \ldots \\
\quad \text { With glucose } \ldots \ldots \ldots \ldots \ldots \ldots \ldots\end{array}$} & & & & & & & & \\
\hline & + & + & + & + & + & + & + & + \\
\hline & + & + & + & + & + & + & + & + \\
\hline \multirow{4}{*}{$\begin{array}{l}\text { No. } 4 \\
\quad \text { Without glucose } \ldots \ldots \ldots \ldots \ldots \ldots \ldots \\
\text { With glucose } \ldots \ldots \ldots \ldots \ldots \ldots \ldots\end{array}$} & \multicolumn{6}{|c|}{ Inoculum } &. $.750^{*}$ & 75 \\
\hline & \multicolumn{6}{|c|}{1} & & \\
\hline & + & + & * & * & * & * & * & \\
\hline & + & + & + & + & + & + & + & + \\
\hline & \multicolumn{6}{|c|}{ Inoculum } & .1900 & 120 \\
\hline
\end{tabular}

$+=$ growth present after 24 hours' incubation.

* = growth present after 48 hours' but not after 24 hours' incubation.

* The number of organisms inoculated per tube was calculated from a plate count made at the start of the experiment.

inant, or was it related to phosphate concentration per se? In order to minimize the possible effects of any traces of other amino acids in experiments designed to elucidate these points thrice recrystallized L-glutamic acid hydrochloride was used in place of the commercially available preparations.

Growth of strain 69 in Frantz, no. 2, and no. 4 media $(0.018 \mathrm{м}, 0.13 \mathrm{M}$, and 0.0018 M inorganic phosphate and thrice recrystallized L-glutamic acid hydrochloride). The size of the minimal inoculum that sufficed to initiate growth in media containing $0.018 \mathrm{M}$ and $0.0018 \mathrm{~m}$ inorganic phosphate was found to be very similar both in the presence and absence of glucose (table 4). It was thought, therefore, that the inhibitory effect described above either was removed by using the purified amino acid or that the range of inhibition by phosphate had not been reached in these experiments.

A comparison of the growth of the organism was made in Frantz, no. 2, and 
no. 4 media containing the recrystallized sugars in equimolar concentration (table 5). In order to balance any possible selection by either sugar or the phosphate concentration all experimental flasks were inoculated with a 24-hour Frantz-glucose culture. The Frantz and the no. 4 cultures grew well with the characteristically rapidly falling $\mathrm{pH}$ of the maltose cultures. In no. 2 medium, however, very little growth was observed in the glucose flasks, but good growth

TABLE 5

Growth of Neisseria meningitidis (strain 69) in the Frantz medium, medium no. 2 , and medium no. 4; glucose* vs. maltose*

\begin{tabular}{|c|c|c|c|c|c|c|c|c|c|c|c|c|}
\hline $\begin{array}{c}\text { IYOPHILED STOCK CULTURE: } \\
7 / 16 / 48\end{array}$ & \multicolumn{12}{|c|}{ ANALYSES } \\
\hline Measured as.................. & \multicolumn{6}{|c|}{$\mathrm{pH}$} & \multicolumn{6}{|c|}{ Growth ( $* 42)$} \\
\hline Hours incubated............... & \multicolumn{3}{|c|}{20} & \multicolumn{3}{|c|}{41} & \multicolumn{3}{|c|}{20} & \multicolumn{3}{|c|}{41} \\
\hline Flask number. & 1 & 2 & 3 & 1 & 2 & 3 & 1 & 2 & 3 & 1 & 2 & 3 \\
\hline 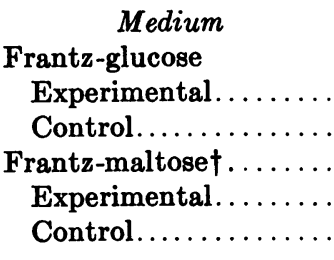 & $\begin{array}{l}7.0 \\
7.3 \\
\\
6.9 \\
7.3\end{array}$ & 6.9 & $\begin{array}{l}7.1 \\
6.9\end{array}$ & $\begin{array}{l}6.9 \\
7.3 \\
\\
6.6 \\
7.3\end{array}$ & $\begin{array}{l}6.9 \\
6.6\end{array}$ & $\begin{array}{l}7.0 \\
6.6\end{array}$ & $\begin{array}{r}30 \\
3 \\
\\
50 \\
0\end{array}$ & $\begin{array}{l}32 \\
53\end{array}$ & $\begin{array}{l}30 \\
50\end{array}$ & $\begin{array}{r}81 \\
0 \\
92 \\
0\end{array}$ & $\begin{array}{l}94 \\
90\end{array}$ & $\begin{array}{r}76 \\
116\end{array}$ \\
\hline $\begin{array}{l}\text { No. } 2 \text { glucose } \\
\text { Experimental....... } \\
\text { Control........... } \\
\text { No. } 2 \text { maltose } \\
\quad \text { Experimental....... } \\
\text { Control............ }\end{array}$ & $\begin{array}{l}7.2 \\
7.3 \\
7.2 \\
7.3\end{array}$ & 7.2 & $\begin{array}{l}7.2 \\
7.2\end{array}$ & $\begin{array}{l}7.2 \\
7.3 \\
7.0 \\
7.3\end{array}$ & $\begin{array}{l}7.2 \\
7.0\end{array}$ & $\begin{array}{l}7.2 \\
7.0\end{array}$ & $\begin{array}{c}0 \ddagger \\
0 \\
31 \\
0\end{array}$ & 36 & 4 & $\begin{array}{r}0 \ddagger \\
0 \\
178 \\
0\end{array}$ & 128 & 17 \\
\hline $\begin{array}{l}\text { No. } 4 \text { glucose } \\
\text { Experimental..... } \\
\text { Control.......... } \\
\text { No. } 4 \text { maltose } † \\
\text { Experimental..... } \\
\text { Control.......... }\end{array}$ & $\begin{array}{l}6.5 \\
7.0 \\
\\
5.7 \\
6.9\end{array}$ & 6.5 & 5.9 & $\begin{array}{l}6.2 \\
6.9 \\
\\
5.3 \\
6.7\end{array}$ & $\begin{array}{l}6.2 \\
5.3\end{array}$ & 5.3 & $\begin{array}{r}38 \\
0 \\
45 \\
0\end{array}$ & 40 & 39 & $\begin{array}{r}85 \\
0 \\
67 \\
1\end{array}$ & 85 & 55 \\
\hline
\end{tabular}

* Recrystallized sugars used.

$\dagger$ Ten $\mathrm{g}$ of maltose used per liter of medium.

$\ddagger$ No viable cells in flask found on subculture on blood agar plate.

was seen in the maltose flasks. As a control of the source of parent cells two different lyophile stock cultures were tested and similar findings were made. The inhibitory effect of the no. 2 medium on the growth of strain 69 was attributed, therefore, to both the presence of glucose and to the high concentration of inorganic phosphate.

Uptake of inorganic phosphate, decrease of reducing substance, and change of pH during the growth of strain 69 in Frantz-glucose (0.5 per cent) and Frantz-mal- 


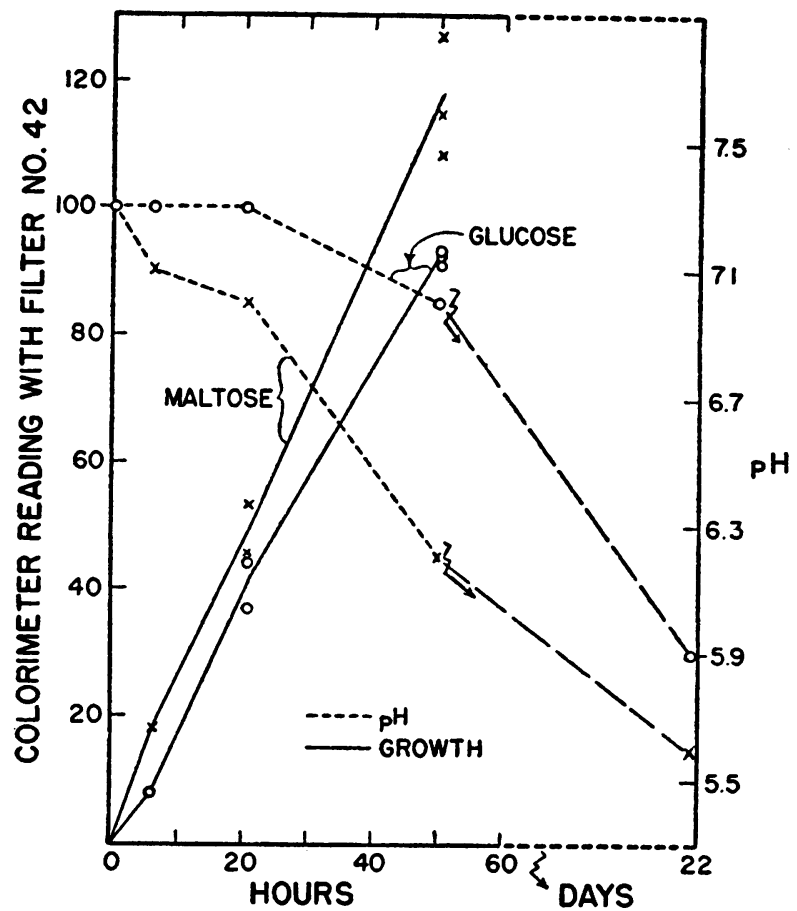

Figure 1. Growth of Neisseria meningitidis (strain 69) in Frantz-glucose (0.5 per cent) and Frantz-maltose (1 per cent) media.

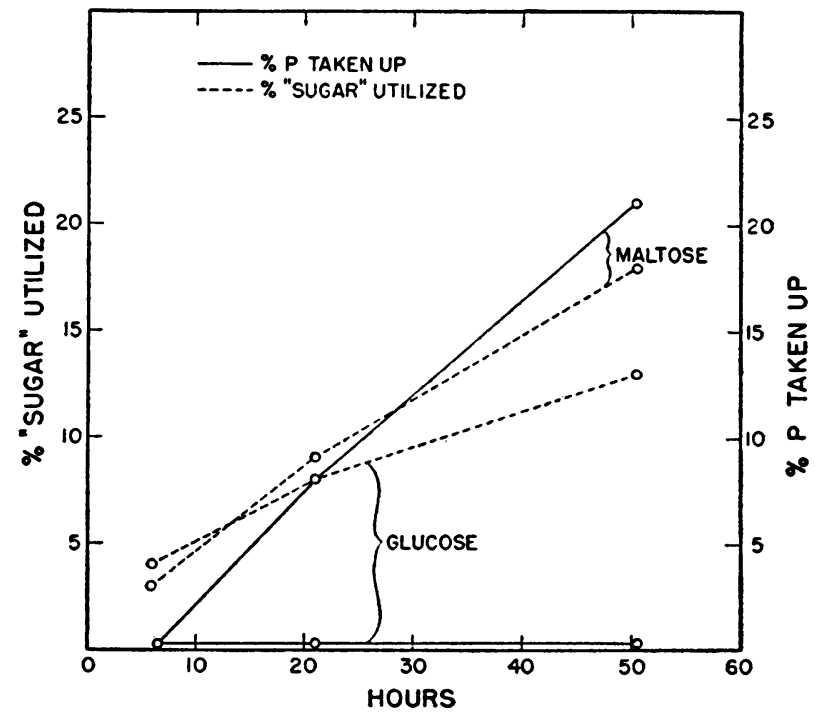

Figure 2. Phosphorus uptake and disappearance of total reducing substances ("sugar utilization") during the growth of Neisseria meningitidis (strain 69) in Frantz-glucose (0.5 per cent) and Frantz-maltose (1 per cent) media. 
tose $(1$ per cent) media. The role of inorganic phosphate in bacterial growth has been investigated extensively. For instance, investigators have observed that high concentrations of inorganic phosphate inhibit a variety of enzyme systems in animal as well as plant tissues (Adler, Euler, et al., 1939; Gayet, 1948; Kearny and Singer, 1949). The finding of a lack of multiplication of our strain of Neisseria meningitidis in a glucose medium containing a relatively high concentration of inorganic phosphate led to a study of the fate of inorganic phosphate during the growth of this organism. A decrease in the concentration of inorganic phosphate was consistently observed in maltose media whereas this change could not be detected in glucose- or sugar-free media. Figures 1 and 2 present observations of one of six similar experiments in which the rate of growth, change in $\mathrm{pH}$, and the disappearance of total reducing substances and of inorganic phosphate were followed. In other experiments the rate of disappearance of inorganic phosphate in the maltose cultures seemed to be independent of the initial concentration of inorganic phosphate. Furthermore, the chemical purity of maltose (Difco vs. recrystallized) did not appear to influence the extent of inorganic phosphate uptake by growing cultures. The fact that in glucose media an over-all change of the concentration of inorganic phosphate was never demonstrated during the growth of the organism and during glucose utilization (figures 1 and 2) suggests different breakdown processes for the disaccharide maltose and for its constituent monosaccharide glucose by this strain of Neisseria meningitidis.

\section{DISCUSSION AND SUMMARY}

It is well known that some bacteria grow more abundantly in the presence of complex sugars than in the presence of their constituent simple sugars. The literature concerned with this problem has been reviewed by Wright (1936) and Dubos (1945). Our observations on the growth of an old laboratory strain of Neisseria meningitidis presented here indicate that the differential rate of growth in the presence of maltose and glucose can be increased by a high concentration of inorganic phosphate $(0.13 \mathrm{M})$ in the glucose medium, whereas the rate of growth with maltose appeared to be unaffected (table 5). It becomes apparent, therefore, that the inhibitory effect of high concentration of inorganic phosphate probably is associated with cellular multiplication in the presence of glucose. By transferring the organism successively in glucose media containing this high concentration of phosphate a "selected" bacterial population resulted possessing the ability to multiply at a rate more nearly equal to its growth rate in the maltose medium (table 3). Even though the rate of growth of these "selected" cultures was similar in both sugar media, their metabolic pattern appeared to show no striking differences from that of the "nonselected" cultures. For example, a greater drop in $\mathrm{pH}$ was observed in the maltose cultures than in the glucose cultures, an increase of "keto acid" occurred in the presence of maltose whereas it did not appear in the presence of glucose, and approximately twice as much of the total reducing substances disappeared in the maltose cultures as in the glucose cultures (table 3 ). This similarity of the quantitative changes observed during 
the growth of the "selected" and "nonselected" cultures suggests that these metabolic activities associated with either maltose or glucose utilization are not primarily related to the phenomenon of growth. Whether or not high concentrations of inorganic phosphate inhibit glucose utilization by "nonselected" cells or inhibit the utilization of the two amino acids present in the various media (L-glutamic acid and L-cystine) remains to be elucidated.

It was noted that the minimal inoculum of "nonselected" cultures that sufficed to initiate growth in glucose media containing $0.13 \mathrm{M}$ inorganic phosphate was about $10^{4}$ times more concentrated than that required in a low phosphate medium $(0.0018 \mathrm{M})$. In addition, it was observed that an increase of inorganic phosphate from $0.0018 \mathrm{M}$ to $0.018 \mathrm{M}$ apparently was without effect on the minimal inoculum required to initiate growth in the presence or absence of glucose (table 4).

The foregoing evidence supports the hypothesis that different "metabolic pathways" are involved in the utilization of the disaccharide maltose and of its constituent monosaccharide glucose by this strain of Neisseria meningitidis. In addition, it was found that during the growth of this organism in chemically defined media all of the accumulated acid in the glucose cultures could be accounted for as volatile acid, which was identified as acetic acid. In the maltose cultures, on the other hand, only from 39 to 45 per cent of the total accumulated acid was volatile acid; the remainder was not identified. Furthermore, a decrease of the concentration of inorganic phosphate of the culture medium was found to occur only when the culture had been grown in the presence of maltose, and it was never detected in the presence of glucose (figures 1 and 2). This phenomenon appeared to be independent of the chemical purity of the maltose, of the initial concentration of inorganic phosphate, and of the history of the culture. Subsequently we shall report on a more detailed investigation of the role of inorganic phosphate in the breakdown of maltose by this organism.

In summary, the following observations have been presented on the growth of an old laboratory strain of Neisseria meningitidis:

In partially defined media the rate of acid accumulation was greater in the presence of maltose than in the presence of glucose.

In chemically defined media all of the accumulated acid was found to be acetic acid in glucose cultures, whereas in maltose cultures only 39 to 45 per cent of the total acid was identified as acetic acid.

In either medium a relatively high concentration of inorganic phosphate retarded growth in the presence of glucose but not with maltose. By transferring the organism successively in glucose media containing this high concentration of inorganic phosphate a "selected" population resulted possessing the ability to multiply at a rate more nearly equal to its growth rate in the maltose medium.

In the maltose cultures a decrease of total reducing substances and the increase of hydrogen ions was consistently greater than in the glucose cultures.

In the maltose cultures inorganic phosphate disappeared from the medium, a change which could not be detected in the glucose cultures. 
These observations support the hypothesis that this strain of Neisseria meningitidis utilizes the disaccharide maltose by a different "metabolic pathway" than that involved in the utilization of its constituent monosaccharide glucose.

\section{REFERENCES}

Adler, E., von Euler, H., Günther, G., and Plass, M. 1939 Isocitric dehydrogenase and glutamic acid synthesis in animal tissues. Biochem. J., 33, 1028-1045.

Barker, S. B., AND Summerson, W. H. 1941 The colorimetric determination of lactic acid in biological material. J. Biol. Chem., 138, 535-554.

Doudoroff, M., Hassid, W. Z., Putman, E. W., Potter, A. L., and Lederberg, J. 1949 Direct utilization of maltose by $E$. coli. J. Biol. Chem., 179, 921-934.

Dubos, R. J. 1945 The bacterial cell. Harvard University Press, Cambridge, Mass. Refer to $p$. 156-168.

Fischer, E. 1898 Bedeutung der Stereochemie für die Physiologie. Z. physiol. Chem., $26,60-87$.

Fitring, C., and Scherp, H. W. 1950 Metabolic studies on Neisseria meningitidis: metabolism of glucose and maltose. Bact. Proc., 1950, 120-121.

Frantz, I. D., JR. 1942 Growth requirements of the meningococcus. J. Bact., 43, 757-761.

GAYET, J. 1948 Etude du métabolisme phosphoré chez le Sterigmatocystis nigra. II. Influence de la concentration en phosphore du liquide nutritif. Bull. soc. chim. biol., 30, 542-547.

Grossowicz, N. 1945 Growth requirements and metabolism of Neisseria intracellularis. J. Bact., 50, 109-115.

HANes, C. S. 1929 An application of the method of Hagedorn and Jensen to the determination of larger quantities of reducing sugars. Biochem. J., 23, 99-106.

Karström, H. 1938 Enzymatische Adaption bei Mikroorganismen. Ergeb. Enzymforsch., 7, 350-376.

KeARNY, E. B., AND Singer, T. P. 1949 The inactivation of L-amino acid oxidase by inorganic phosphate and arsenate. Arch. Biochem., 21, 242-245.

LOWERY, O. H., AND LOPEZ, J. A. 1946 The determination of inorganic phosphate in the presence of labile phosphate esters. J. Biol. Chem., 162, 421-428.

Monod, M. J., ANd Torrinni, A. M. 1950 De l'amylomaltase d'Escherichia coli. Ann. inst. Pasteur, 78, 65-77.

Osburn, O. L., Wood, H. G., and Werkman, C. H. 1936 Determination of volatile fatty acids by the partition method. Ind. Eng. Chem., Anal. Ed., 8, 270-275.

Pelczar, M. J., JR., AND Doetsch, R. N. 1949 On the direct fermentation of maltose. Science, 110, 256.

RAKE, G. 1933 Studies on meningococcus infection. I. Biological properties of "fresh" and "stock" strains of meningococcus. J. Exptl. Med., 57, 549-560.

Schales, O., ANd Schales, S. S. 1945 A simple method for the determination of glucose in blood. Arch. Biochem., 8, 285-292.

Scherp, H. W., and Fitting, C. 1949 The growth of Neisseria meningitidis in simple chemically defined media. J. Bact., 58, 1-9.

Sealock, R. R. 1941 The determination of amino acids of the dextro or unnatural configuration. Science, 94, 73-74.

SomoGYI, M. 1930 A method for the preparation of blood filtrates for the determination of sugar. J. Biol. Chem., 86, 655-663.

SUmNer, J. B., AND Somers, G. F. 1944 The preparation of glucose-1-phosphate. Arch. Biochem., 4, 11-13.

Willstätter, R., and Rohdewald, M. 1937 tber die erste Phase der Gärung durch Hefe. Z. physiol. Chem., 247, 269-280.

Wright, H. D. 1936 Direct fermentation of disaccharides and variation in sugar utilization by Streptococcus thermophilus. J. Path. Bact., 43, 487-501. 